\title{
Advanced Pharmacotherapy Evidenced by Pathogenesis of Autism Spectrum Disorder
}

\author{
Yeon Jung Lee ${ }^{1}$, Soo Hyun Oh${ }^{2}$, Chanmin Park', Minha Hong ${ }^{7}$, Ah Rah Lee ${ }^{3}$, Hee Jeong Yoo ${ }^{4}$, Chan Young Shin ${ }^{5}$, \\ Keun-Ah Cheon ${ }^{6}$, Geon Ho Bahn ${ }^{1}$ \\ ${ }^{1}$ Department of Psychiatry, Kyung Hee University School of Medicine, Seoul, ${ }^{2}$ Department of Life Sciences, Ewha Womans University, \\ Seoul, ${ }^{3}$ Kyung Hee University School of Medicine, Seoul, ${ }^{4}$ Department of Neuropsychiatry, Seoul National University Bundang Hospital, \\ Seongnam, ${ }^{5}$ Department of Pharmacology, Konkuk University School of Medicine, Seoul, ${ }^{6}$ Department of Psychiatry, Yonsei University \\ College of Medicine, Seoul, ${ }^{7}$ Department of Psychiatry, Dankook University Medical College, Chungnam, Korea
}

\begin{abstract}
In clinical practice, pharmacological treatment is mostly focused on behavioral symptoms in everyday life. Nevertheless, persistent effort continues to develop medication for causal treatment. Recent changes in diagnostic criteria from Diagnostic and Statistical Manual of Mental Disorders, 4th edition, text revision (DSM-IV-TR) to DSM-5 would affect not only diagnosing approaches, but also therapeutic approaches. Because previous pervasive developmental disorders have been integrated into a single entity, the autism spectrum disorder (ASD), we have to prepare for what medications are valuable for the ASD. In this article, we reviewed the following etiological treatment: acetylcholine and glutamate related medicine; amino acid medicine such as secretin, endogenous opioid, and oxytocin; complementary and alternative medicine such as chelating agents, vitamins, and omega-3; promising drugs related to the scope of pharmacogenetics currently under study.
\end{abstract}

KEY WORDS: Child development disorders, pervasive; Drug therapy; Etiology.

\section{INTRODUCTION}

Autism spectrum disorder (ASD) is a neurodevelopmental disorder characterized by impaired social skills, communication deficits and repetitive behaviors, interests or activities. ${ }^{1)}$ It is frequently associated with comorbid disorders such as intellectual disability, obsessive compulsive disorder, epilepsy, Tourette syndrome, attention deficit/hyperactivity disorder (ADHD), tuberous sclerosis and Fragile X syndrome (FXS) ${ }^{2)}$ The Centers for Disease Control and Prevention ${ }^{3)}$ currently estimates the prevalence of ASD in the USA at 1 in 88 children ( 1 in 54 boys and 1 in 252 girls). ASD affects more children than are affected by diabetes, acquired immune deficiency syndrome (AIDS), cancer, cerebral palsy, cystic fibrosis, muscular dystrophy or Down's syndrome combined. ${ }^{3)}$ Although genetic predisposition and environmental contributors have been implicated in the pathophysiology of

\footnotetext{
Received: February 4, 2014 / Revised: March 17, 2014

Accepted: March 20, 2014

Address for correspondence: Geon Ho Bahn, MD, PhD

Department of Psychiatry, Kyung Hee University School of Medicine,

23 Kyungheedae-ro, Dongdaemun-gu, Seoul 130-702, Korea

Tel: +82-2-958-8556 Fax: +82-2-957-1997

E-mail: mompeian@khu.ac.kr
}

ASD, the precise mechanisms underlying the pathophysiology of this disorder remain unknown and there are no established methods of prevention or cure. ${ }^{1)}$

The Diagnostic and Statistical Manual of Mental Disorders, 5th edition (DSM-5; American Psychiatric Association [APA] 2013) ${ }^{4)}$ was published in 2013 and combined several previously separate disorders under the ASD umbrella. These disorders are pervasive developmental disorder (PDD) including autistic disorder, Asperger's disorder, childhood disintegrative disorder and PDD not otherwise specified (PDD NOS). Rett's disorder was excluded as a genetic disorder. The DSM-5 now conceptualizes the separate disorders as a single condition with different levels of symptom severity in two core domains; (1) social communication and social interaction, (2) restricted repetitive behaviors, interests, and activities. ${ }^{4)}$ Such changes could influence diagnostic methods and therapeutic approaches which would raise both concerning and favoring perspectives. ${ }^{5)}$ The concerned position argues that the number of patients taking medication could be inflated, since separate disorders are combined into a single disorder. Also, since the new category is a re-organization based on symptoms, not a categorization

(a) This is an Open-Access article distributed under the terms of the Creative Commons Attribution Non-Commercial License (http://creativecommons.org/licenses/by-nc/3.0) which permits unrestricted non-commercial use, distribution, and reproduction in any medium, provided the original work is properly cited. 
Table 1. Drugs and substrates based on etiological pathogenesis of autism spectrum disorder

\begin{tabular}{|c|c|c|}
\hline Etiological classification & Drugs and substrates & Design, setting and sample \\
\hline \multirow[t]{5}{*}{ Cholinergics } & Tacrine & 2-week, open-label, 20 mg daily, $(n=3)^{11)}$ \\
\hline & Rivastigmine & 12-week, open-label, $0.4 \mathrm{ml}$ twice daily, $(\mathrm{n}=32)^{12)}$ \\
\hline & Galantamine & 12-week, open-label, 2 mg twice daily, $(n=13)^{14)}$ \\
\hline & Donepezil & 6-week, RCT, additional 6-week open-label, 2.5 mg daily, $(n=43)^{17)}$ \\
\hline & & 10-week, parallel-groups, RCT, $10 \mathrm{mg}$ daily, $\left.(n=34)^{18}\right)$ \\
\hline \multirow[t]{6}{*}{ Glutamatergics } & NMDA antagonists & 10-week, RCT, memantine $20 \mathrm{mg}$ daily, $(n=40)^{27)}$ \\
\hline & & $\begin{array}{l}\text { 8-week, open-label, STX209 } 10 \mathrm{mg} \text { twice daily (age 6-11 years) or three times daily (age } \\
12-17 \text { years), }(n=32)^{28)}\end{array}$ \\
\hline & & 4-week, open trial, $20 \mathrm{mg}$ daily, $(n=4)^{29)}$ \\
\hline & & 8-week, open-label, memantine $0.4 \mathrm{mg} / \mathrm{kg}$ daily, $\left.(n=14)^{30}\right)$ \\
\hline & mGluR antagonists & 6-hour, pilot open-label, fenobam 50-150 mg, $(n=12)^{32)}$ \\
\hline & GABA agonists & 4-week, crossover, RCT, AFQ056 150 mg twice daily, $(n=30)^{33)}$ \\
\hline \multirow[t]{5}{*}{ Neuropeptides } & Secretin & 8 -week, single-blind cross-over, 8-12 units/kg IV, $(n=12)^{40)}$ \\
\hline & Naltrexone & 6-week, parallel-group, $1 \mathrm{mg} / \mathrm{kg}$ daily, $(n=41)^{45)}$ \\
\hline & Oxytocin & 4-hour, crossover, RCT, gradually titrated up IV, $(n=15)^{54)}$ \\
\hline & & $\begin{array}{l}\text { 45-minute, crossover, RCT, } 18 \mathrm{IU} \text { (age } 12-15 \text { years) or } 24 \mathrm{IU} \text { (age 16-19 years) IN, }(n=16)^{55)} \\
\text { l-week. RCT } 24 \mathrm{IU} I \mathrm{~N}(\mathrm{n}=13)^{56)}\end{array}$ \\
\hline & & 4-week, open-label, 8 IU daily, $(n=1)^{57)}$ \\
\hline \multirow[t]{4}{*}{ CAM } & Chelating agents & 4-hour, open-label, DMSA $10 \mathrm{mg} / \mathrm{kg},(\mathrm{n}=95)^{71)}$ \\
\hline & & $\begin{array}{l}\text { 13-months, } \mathrm{RCT} \text {, succimer } 1,050 \mathrm{mg} / \mathrm{M} 2 \text { daily for the first } 7 \text { days }(700 \mathrm{mg} / \mathrm{M} 2 \text { daily } \\
\text { thereafter), }(n=780)^{72)}\end{array}$ \\
\hline & Vitamins & $\begin{array}{l}\text { 3-month, RCT, multi-vitamin/mineral supplement, different dosage each, three times } \\
\text { daily, }(n=141)^{74)}\end{array}$ \\
\hline & Omege-3 & $\begin{array}{l}\text { 6-weeks or 12-weeks, RCT, EPA } 0.84 \mathrm{~g} \text { and DHA } 0.7 \mathrm{~g} \text { IV daily; EPA } 0.7 \mathrm{~g} \text { and DHA } 0.46 \\
\text { g IV daily, }(\mathrm{n}=37)^{83)}\end{array}$ \\
\hline \multirow[t]{4}{*}{ Promising drugs } & N-acetylcysteine & 12-week, RCT, 900 mg up to 2,700 mg daily, $(n=33)^{91)}$ \\
\hline & Purinergic antagonists & 18-week, C57BL/6J mice, suramin 10 or $20 \mathrm{mg} / \mathrm{kg}$ IP weekly, $(n=168)^{92)}$ \\
\hline & Rapamycin & Tsc2+/- mice, different dosage and route ${ }^{103)}$ \\
\hline & PTEN modulators & $\begin{array}{l}\text { PTEN haplo-insufficient mice aged } 20-29 \text { weeks showed aberrant social behavior like } \\
\text { autism. }{ }^{109)}\end{array}$ \\
\hline
\end{tabular}

RCT, randomized controlled trial (with placebo controlled); CAM, complementary and alternative medicine; NMDA, N-methyl-D-aspartate; mGluR, metabotropic glutamate receptor; GABA, $\gamma$-aminobutyric acid; succimer, dmercaptosuccinic acid; DMSA, 2, 3-dimercaptosuccinic acid; EPA, eicosapentaenoic acid; DHA, docosahexaenoic acid; PTEN, phosphatase and tensin homolog deleted on chromosome 10; IN, intranasal; IV, intravenous; IP, intraperitoneal.

based on etiological or biological evidence, conservative treatment would still continue. ${ }^{6)}$ However, there could be positive effects in matters such as applying and assessing therapeutic effects since assessment could be done by a single standard. In other words, results from previous studies on five separately diagnosed patients or disorders may prove difficult to interpret and combine while a single diagnostic approach to similar developmental disorders simplifies the investigation of etiology and pathogenesis. A way to maximize the advantages of such changes as a single disorder would be to investigate the etiology and pathogenesis by medication. ${ }^{7)}$ Hence, the authors intend to contribute to the research for pathogenesis and etiological treatment of ASD by reviewing medicine based on pathogenic approach besides current conservative treatments (Table 1).

\section{MAIN SUBJECTS}

\section{Cholinergics}

\section{Mechanism}

Acetylcholine (Ach) acts at two different types of cholinergic receptors, namely muscarinic and nicotinic receptors. Muscarinic receptors bind Ach as well as other agonists and antagonists. Nicotinic receptors are less abundant than the muscarinic type in the central nervous system. Ach is removed from the synapse through hydrolysis into CoA and choline by the enzyme acetyl cholinesterase. Ach modulates attention, novelty seeking, and memory via the basal forebrain projections to the cortex and limbic structures. ${ }^{8)}$ Recent animal studies show the amelioration of autism-relevant phenotypes, including decreasing cognitive rigidity, improving social preference, and enhancing social interaction through the augmentation of Ach in the synaptic cleft by inhibiting acetylcholinesterase. ${ }^{9)}$ Interestingly, cholinergic enhance- 
ment is shown to positively modulate selective attention and emotional processing, which are impaired in autistic individuals. $^{10)}$

\section{Clinical implication}

\section{Tacrine}

Niederhofer ${ }^{11)}$ reported that Tacrine may be modestly effective in the short-term treatment of irritability, hyperactivity, inadequate eye contact, and inappropriate speech in children with autistic disorder. Although there was no sign of hepatotoxicity in a short-term trial with Tacrine, its registration in many countries has been cancelled because of late hepatotoxicity.

\section{Rivastigmine}

Chez et $a l .{ }^{12)}$ documented statistically significant improvements on behavioral measures, expressive vocabulary, and core features of autism in a 12-week, open label trial of rivastigmine involving 32 children with ASD.

\section{Galantamine}

The use of galantamine (4 mg/day) enhanced expressive language in an open-label study of three adults with autism. ${ }^{13)}$ Nicolson et al. ${ }^{14)}$ reported that 13 children with autism experienced significant improvements in irritability, social withdrawal, and inattention with galantamine (4 to $24 \mathrm{mg} /$ day) in a 12-week open-label study, as rated by parents. Anger and autistic behavior were also reduced when clinicians observed.

Niederhofer et al. ${ }^{15)}$ conducted a placebo controlled, double blind crossover randomized controlled trial investigating the efficacy of galantamine in 20 boys with autistic disorders. Treatment with galantamine was well tolerated and led to improvements in irritability, hyperactivity, eye contact and inappropriate speech compared with placebo.

\section{Donepezil}

From a retrospective study of donepezil in 8 children with autism, the irritability and hyperactivity subscales were decreased, but the inappropriate speech, lethargy, and stereotypies subscales did not change. ${ }^{16)}$ In a 6-week randomized double blind placebo controlled study of 43 children with ASD, the use of donepezil (1.25 to $2.5 \mathrm{mg} / \mathrm{d}$ ) led to improvements in expressive and receptive language as well as a decrease in overall autistic behavior compared with placebo. ${ }^{17)}$ Handen et al. ${ }^{18)}$ reported that short-term treatment with donepezil may have limited impact on cog- nitive functioning in ASD.

\section{Glutamatergic and GABA}

\section{Mechanism}

Glutamate, the major excitatory neurotransmitter, is highly concentrated throughout the brain and is crucial for neuronal plasticity and maintenance of cognitive functions. ${ }^{19)}$ However, excess glutamate has been shown to be a potent neurotoxin that leads to neuronal cell death ${ }^{19)}$ and is deemed to play a role in the pathophysiology of some neuropsychiatric disorders, such as schizophrenia, obsessive-compulsive disorder and Alzheimer's disease. ${ }^{20)}$ Several mechanisms related to a hyperglutamatergic hypothesis of autism are being proposed. First, Fatemi et $a .^{21)}$ reported glutamate increase due to dysfunctions in enzymes responsible for converting glutamate to gamma-aminobutyric acid (GABA). Yip et al. ${ }^{22)}$ reported consistent findings regarding increase in glutamate concentration due to fewer Purkinje cells in autistic cerebella and related enzymes. Second, there are proposals suggesting that glutamate transporters (excitatory amino acid transporters), which translocate glutamate from endothelial cells to the extracellular fluids, are involved in autism's pathophysiology. ${ }^{23)}$ Third, Brown et al. ${ }^{24)}$ and Ortinski et $a l{ }^{25)}$ reported that decreased glutamine and increased glutamate due to dysfunctions in the glutamate-glutamine cycle is significantly involved in ASD development.

\section{Clinical implication}

\section{N-Methyl-D-aspartate (NMDA) antagonists}

Blocking glutamatergic transmission with MK-801 or memantine treatment, and to a lesser extent with 2-methyl-6-(phenylethynyl) pyridine treatment, reversed the impaired social behaviors and seizure susceptibility of prenatally valproate-exposed rat offspring used as an animal model of ASD. ${ }^{26)}$

From four open label human studies investigating the use of memantine for PDD, ${ }^{27-30)}$ subjects taking memantine demonstrated symptomatic improvement, in particular behavioral. Nevertheless, the lack of double-blind design or control groups is considered a weakness of these studies. $^{31)}$

\section{Metabotropic glutamate receptor (mGluR) antagonists}

The first mGluR antagonist to go into human trials was fenobam, which was studied in 12 patients with FXS in a pilot open-label study. ${ }^{32)}$ About half of the patients 
showed improved eye contact and 25\% showed improvements in social interaction with a single dose of the drug. The next mGluR antagonist to reach human trials was AFQ056. This agent was studied in a double-blind placebo-controlled crossover study of 30 patients with FXS. ${ }^{33)}$ Following 4 weeks of treatment, there was no significant improvement found when the entire sample was analyzed as a single group. However, post hoc analysis revealed that the seven patients with fully methylated mutations showed significant improvements in the Aberrant Behavior Checklist (ABC), Clinical Global Impression Scale (CGI) and the Social Responsiveness Scale as well as specific improvements in subscales measuring stereotypic behavior, hyperactivity, inappropriate speech and restricted interests. This effect was not observed in patients with partial methylation at the Fragile $\mathrm{X}$ Mental Retardation-1 (FMR1) promoter (the majority of patients in the original cohort).

\section{$\gamma$-Aminobutyric acid (GABA) agonists}

STX209, a GABA agonist, was administered to 63 patients with FXS in a double-blind placebo-controlled crossover phase II study. ${ }^{34)}$ Following four weeks of treatment, results indicated an improvement in the parents' ratings for the three most problematic behaviors for their child as well as in the ABC Avoidance Scale (ABC-AS). However, there was no significant effect on other validated FXS factor scores on the ABC. When a subgroup of more severely affected patients was analyzed separately, in addition to the above effects, significant improvements were observed on the Vineland-Socialization measure of adaptive functioning and on the CGI Scale. Anecdotal reports also indicated that the patients were more communicative when on STX209 compared to the placebo. Erickson et al. ${ }^{35)}$ reported that improvements were observed on several outcome measures including the ABCIrritability (the primary endpoint) and the Lethargy/Social Withdrawal subscales, the Social Responsiveness Scale, the Children's Yale-Brown Obsessive Compulsive Scale Pervasive Developmental Disorder (CY-BOCS-PDD), and clinical global impression scales.

\section{Neuropeptides}

Unlike cholinergics or glutamatergics, neuropeptide medication and substances are based on different mechanisms and thus are described separately.
Secretin

\section{Mechanism}

The 27 amino-acid polypeptide secretin is a gastrointestinal polypeptide usually used to treat peptic ulcers and evaluate pancreatic function. ${ }^{36)}$ Some animal study results have also suggested that secretin affects the central nervous system and may function as a neurotransmitter. ${ }^{37,38)}$

Interest in secretin for the treatment of ASD stemmed from a non-blinded, uncontrolled case series of three children with ASD who received synthetic intravenous secretin during a routine endoscopy evaluation for gastrointestinal problems. ${ }^{39)}$ The report noted social, cognitive, and communicative gains after the first infusion and after a second infusion given weeks later. Following this report, the use of secretin became widespread.

\section{Clinical implication}

Children with autism have symptoms consistent with a central 6R-5, 6, 7, 8-tetrahydro-L-biopterin (BH4) deficiency. ${ }^{40)} \mathrm{BH} 4$ deficiency can result in low production of monoamine neurotransmitters, including serotonin, dopamine, and norepinephrine. There is a significant amount of evidence that deficits in these monoamine neurotransmitters are present in some children with autism. Research results suggest that secretin ameliorates core symptoms of ASD through the activation of metabolic turnover of dopamine in the central nervous system via BH4. ${ }^{40)}$ Recently, thorough review of 16 randomized trials with a placebo control group involving over 900 children with ASD was conducted. Williams et al. ${ }^{41)}$ concluded that there was no evidence that either a single or multiple dose of intravenous secretin improved the main problems seen in ASD. Currently it should not be recommended or administered as a treatment for ASD. ${ }^{41)}$

Nonetheless, it may be worthwhile to review the results of Toda et $_{\text {al. }}{ }^{40)}$ which suggest that secretin can be effective for ASD patients who have increased BH4 levels. Toda $e t$ al $^{40)}$ evaluated the clinical effects of intravenously administered secretin in 12 children with autism. The homovanillic acid and BH4 levels in cerebrospinal fluid were increased in all children with improvements in the Autism Diagnostic Interview-Revised (ADI-R) score. In contrast, patients without elevated BH4 levels showed no improvement in the score. These findings suggest that secretin activates metabolic turnover of dopamine in the central nervous system via $\mathrm{BH} 4$, subsequently improving symptoms. ${ }^{40)}$ Consequently, the role of secretin and its 
mechanism of action in the central nervous system should be investigated for possible applications with patients who have changes in brain metabolism.

\section{Naltrexone}

\section{Mechanism}

Naltrexone is an opioid receptor antagonist that is commonly used for the treatment of alcoholism and opioid dependence. ${ }^{42)}$ It has also been used to treat children with autism based on the hypothesis that autism is related to hypersecretion of brain opioids, reflecting dysfunction in the pineal-hypothalamic-adrenal axis. ${ }^{43)}$ Several studies have reported that naltrexone decreases challenging aspects of autism such as self-injurious behavior (SIB), ${ }^{44)}$ and hyperactivity. ${ }^{45)}$ One of the theories put forth to explain the symptoms of ASD involves the dysfunction of the endogenous opioid system which is involved in hedonic processing of reward, positive reinforcement, impulsivity, and potentially craving in alcohol dependence. The brain opioid hypothesis of social attachment posits that reductions in opioid activity should increase the desire for social companionship, while increases in this system should reduce the need for affiliation. ${ }^{46)}$

\section{Clinical implication}

Campbell et $a{ }^{45)}$ randomly assigned 41 hospitalized young children (ages 2.9-7.8 years) with autism to either three weeks of naltrexone $(1 \mathrm{mg} / \mathrm{kg} / \mathrm{day})$ or placebo treatment. Patients treated with naltrexone showed significant improvement in hyperactivity, but no improvement in learning or core autistic symptoms. Symons et $a l .{ }^{44)}$ reviewed published literature from 1983 to 2003 documenting the use of naltrexone for the treatment of SIB. A sample of 27 research articles involving 86 subjects was reviewed. Eighty percent of the subjects showed improvements during naltrexone administration and $47 \%$ of the subjects exhibited reductions in SIB by as much as $50 \%$ or greater. In studies reporting dose levels in milligrams, males were more likely than females to respond. ${ }^{44)}$ No significant relations were found between treatment outcomes and autism status or form of self-injury. Subsequently, naltrexone may be an option worthy of consideration in treatment-refractory SIB, but the overarching conclusion from the mixed literature on this drug is that there is a pressing need for studies that will help to identify potential responders from within the heterogeneous population of persons with intellectual disability who self-injure. $^{47)}$

\section{Oxytocin}

\section{Mechanism}

Oxytocin (OT), a neuropeptide that is secreted from the posterior pituitary, plays an important role in social affiliation and attachment. ${ }^{48)}$ It is also a promising candidate for treatment of social impairments in ASD patients. OT is mainly synthesized in magnocellular neurons of the supraoptic and paraventricular nuclei of the hypothalamus that project to the posterior pituitary. From the pituitary, it is released into the bloodstream to act as a hormone. In addition, neurons in the paraventricular nuclei project to various limbic, mid- and hindbrain structures containing OT receptors. Within the brain, OT can act both as a neurotransmitter and as a neuromodulator. ${ }^{49)}$

The OT receptor gene $(O X T R)$ is located on chromosome $3 \mathrm{p} 25$, spans $17 \mathrm{~kb},{ }^{50)}$ and encodes a 389 amino acid polypeptide with seven transmembrane domains belonging to the class I G-protein-coupled receptor family. ${ }^{51)}$ Genetic variations influencing the number, organization, or functioning of OT receptors would be expected to influence the efficacy of the OT signal in the brain. Indeed, initial studies have linked variations in $O X T R$ to susceptibility for mental disorders characterized by social deficits, such as ASD. ${ }^{52,53)}$

\section{Clinical implication}

OT has been implicated in states of aberrant social function. Previous attempts to improve social deficits in young ASD patients via OT nasal spray revealed positive results, specifically, improved retention of affective speech comprehension, ${ }^{54)}$ enhanced mind-reading performance, ${ }^{55)}$ more frequent engagement in positive social interactions, and enhanced feelings of trust and preference towards partners within positive interactions. ${ }^{56)}$

There is a case report of a 16-year-old girl with ASD whose social impairments and secondary disabilities were improved by long-term ( 2 month) nasal oxytocin administration without any adverse effects. ${ }^{57)}$ Social interaction, communication, and aggressive behavior were all improved. Her ABC scores decreased from 69 to 7 . This case suggests that long-term oxytocin administration is a safe treatment for improving social impairments even in female patients with ASD.

At a biochemical level, it is still unclear whether peripheral OT levels are correlated with OT levels in the brain, ${ }^{58)}$ and whether and how intranasally administered OT reaches the receptors in the brain. ${ }^{59)}$ If the pathway responsible for the behavioral effects of OT treatment is initially pe- 
ripheral followed by increased central OT levels rather than initially central, then nasal administration is a suboptimal method for increasing central OT levels. ${ }^{60)}$ Despite not knowing the mechanism for how OT penetrates the limbic system and reaches its receptors, individuals diagnosed with autism or related disorders seem to profit most from application of OT, and their social-communicative skills might improve significantly, based on the results of the trials. ${ }^{48)}$

\section{Complementary and Alternative Medicine (CAM)}

Although numerous CAM lacks scientific evidence, it is broadly used due to its recognition as a treatment with lesser side effects than general medicine. ${ }^{61)}$ The percentage of children with ASD in the USA who are reported to receive CAM is about $2-50 \%{ }^{62)}$ and in some studies, it is estimated to be up to $50-70 \% .{ }^{61)}$ Levy and Hyman ${ }^{61)}$ classified CAMs according to the strength of the evidence: grade A with randomized controlled trials, reviews and/or meta-analyses; grade B with other evidence such as isolated well-designed controlled and uncontrolled studies; grade $\mathrm{C}$ with case reports or theories. For example, vita$\min \mathrm{C}$ and omega- 3 fatty acids are placed as grade $\mathrm{B}$ and chelation as grade C. Previous studies on CAM up to the current date need to be investigated ${ }^{63)}$ and we reviewed commonly used substances.

\section{Chelating agents}

\section{Mechanism}

Some articles emphasized that rising levels of autism could be related to environmental exposure to toxins. ${ }^{64,65)}$ DeSoto and Hitlan ${ }^{66)}$ reviewed published research studies examining the relationship between toxic metal exposures and the risk of a subject being diagnosed with an ASD: $74 \%$ (43 of 58) of the studies showed a significant relationship between an ASD and toxic metal exposure. Hair analysis showed that autistic children have elevated hair concentrations for aluminum, arsenic, cadmium, mercury, antimony, nickel, lead, and vanadium. ${ }^{67)}$ Also, there was a significant positive correlation between lead and verbal communication $(p=0.020)$ as well as general impression $(p=0.008)$. These data support the theory that heavy metals play a role in the development of ASD. Among the heavy metals, mercury and lead especially have been the main focus of research on the causes of ASD symptoms. Low level of mercury has clearly been demonstrated to cause specific damage to developing human brain cells. ${ }^{68)}$ Even very low level of lead exposure in childhood may cause lifelong impairment of attention, memory and learning. ${ }^{69)}$

\section{Clinical implication}

It is estimated that ASD children have impaired methylation, sulfation and anti-oxidant processes associated with the detoxification process of heavy metals. ${ }^{70)}$ Urine tests are better conducted by the using chelating agent, ethylene diamine tetraacetic acid (EDTA) or 2, 3-dimercaptosuccinic acid (DMSA) to measure heavy metal concentrations in the body. ${ }^{71)}$

The oral chelater, meso-2, 3-DMSA is the most commonly used chelating agent. It binds with heavy metals of the opposite charge and results in an increase in urinary excretion of heavy metals from the body. ${ }^{66)}$ However, it does not improve cognition, behavior, or neuropsychological function. ${ }^{72)}$ Despite the limitations of the studies, the cumulative findings suggest that chelation might be a viable form of treatment in some individuals with an ASD who have elevated heavy metal content or biochemical changes. $^{\text {.3) }}$

\section{Vitamins}

\section{Mechanism}

Vitamins are essential for human health due to their critical function as enzymatic cofactors for numerous reactions in the body. ${ }^{74)}$ Oral vitamin supplementation is beneficial in improving the nutritional and metabolic status of children with ASDs. These include improvements in methylation, glutathione, oxidative stress, sulfation, adenosine triphosphate (ATP), nicotinamide adenine dinucleotide phosphate (NADPH), and oxidized form NADPH $(\mathrm{NADP}+) .{ }^{74)}$ A pilot study suggests that plasma concentrations of the exogenous antioxidants, vitamins $\mathrm{E}$ and $\mathrm{A}$, as well as lycopene in autistic subjects were at insufficient levels. ${ }^{75)}$ The environment influences responsive genes and, subsequently the genome. Vitamin D is a neurosteroid $^{76)}$ and follows this type of genetic organization. ${ }^{77)}$ Cui et $a{ }^{78)}$ have determined that vitamin D is important for neural development and its deficiency negatively alters brain structure and function.

\section{Clinical implication}

A randomized, double blind, placebo-controlled study on the effects of supplements on ASD was conducted for three months. One group received multivitamin and mineral supplements, while the other group received placebos. ${ }^{74)}$ The supplement group showed significantly great- 
er improvements than the placebo group on the Parental Global Impressions-Revised (PGI-R). The most significant improvements on the PGI-R subscales were in the areas of hyperactivity, tantrumming, overall, and receptive language.

Vitamin D has also been actively studied. A Japanese case report showed that ASD children improved in symptoms during the summer. ${ }^{79)}$ Vitamin D is highly seasonal with a summertime surfeit and a wintertime deficit. It also has remarkable antioxidant, anti-inflammatory, and anti-autoimmune properties. Animal experiments provide data for vitamin D's role in brain proliferation, differentiation, neurotrophism, neuroprotection, neurotransmission, and neuroplasticity. ${ }^{80)}$ It can be assumed that vitamin D may have an effect on improving ASD symptoms.

According to a survey of 539 physicians, vitamin/mineral supplements are the most widely recommended medical interventions for autism, and are recommended by $49 \%$ of physicians for children with autism. ${ }^{81)}$ Vitamin supplement is well-tolerated, with few side effects, therefore it can be a candidate for adjuvant therapy for ASDs. However, more studies on the effectiveness of vitamins for ASD treatment are necessary.

\section{Omega-3}

\section{Mechanism}

Essential fatty acids are polyunsaturated fatty acids which are not produced by the human body but are necessary for normal development and functioning of the brain and immune system. ${ }^{82)}$ There are several key types of essential fatty acids. Fish and seafood are major sources of eicosapentaenoic acid (EPA) and docosahexaenoic acid (DHA), which are long chain omega-3 fatty acids. ${ }^{83)}$ It has been suggested that difficulties associated with ASD may be explained in part by lack of omega-3 fatty acids, and that supplementation of these essential fatty acids may lead to an improvement of symptoms. ${ }^{83)}$ Omega-3 deficits or imbalances have been linked to various neurodevelopmental disorders, such as ADHD, dyslexia, and dyspraxia. ${ }^{84)}$

\section{Clinical implication}

From the meta-analysis on the efficacy of omega-3 fatty acids for three primary outcomes (social interaction, communication, and stereotypy) and one secondary outcome (hyperactivity), 37 children diagnosed with ASD who were randomized into groups that received either omega-3 fatty acids supplementation or a placebo were included. ${ }^{83)}$
From this meta-analysis, there was no evidence that omega-3 supplements had an effect on social interaction, communication, stereotypy, or hyperactivity. To date there is no evidence-based proof that omega-3 fatty acids supplementation is effective as a treatment for autism. ${ }^{85)}$

\section{Promising Drugs}

New therapeutic methods including at the gene and chromosome levels, are currently being studied to regulate ASD core symptoms. We intend to review the commonly used agents.

\section{$\mathrm{N}-$ Acetylcysteine}

\section{Mechanism}

$\mathrm{N}$-Acetylcysteine (NAC) targets a diverse array of factors germane to the pathophysiology of multiple neuropsychiatric disorders including glutamatergic transmission, the antioxidant glutathione, neurotrophins, apoptosis, mitochondrial function, and inflammatory pathways. ${ }^{86)} \mathrm{NAC}$ is the $\mathrm{N}$-acetyl derivative of the amino acid L-cysteine and is rapidly absorbed following oral administration. ${ }^{87)}$ L-Cysteine is rapidly oxidized to cystine in the pro-oxidant milieu of the brain. Cystine is the substrate of the cystine-glutamate antiporter, which shuttles glutamate out of the cell in exchange for cystine, thereby regulating extracellular glutamate levels and facilitating cysteine entry into the cell. ${ }^{88)}$ Inside the cell, cystine can be reduced to cysteine, which is the rate-limiting component of the key endogenous antioxidant molecule glutathione (GSH). ${ }^{89)}$ The ability of NAC to regulate both cysteine and - glutamate antiporter activities as well as the biosynthesis of GSH is the key to its therapeutic efficacy. In autism, dysregulation of redox biology, inflammation, and glutamate transmission have been noted. ${ }^{90)}$

\section{Clinical implication}

From recent tantalising data on the efficacy of NAC in autism, participants were administered $900 \mathrm{mg}$ daily for 4 weeks then gradually increased to $2,700 \mathrm{mg}$ daily over a period of 8 weeks. $^{91)}$ In this 12-week, double-blind, randomized, placebo-controlled study of NAC, significant improvements on the $\mathrm{ABC}$ irritability subscale in the NAC group were reported. Improvements were also observed on the Repetitive Behavior Scale-Revised stereotypies measure and mannerisms scores of Social Responsiveness Scale. 


\section{Purinergic antagonists}

\section{Mechanism}

Mitochondria act to connect genes and environments by regulating gene-encoded metabolic networks according to changes in the chemistry of the cell and its environment. ${ }^{92)}$ Mitochondrial ATP, adenosine diphosphate (ADP), uridine triphosphate (UTP), and uridine diphosphate (UDP) are mitokines. Mitokines are molecules produced by mitochondria that act as signaling molecules when outside the cell, and have separate metabolic functions inside the cell. Outside the cell, they bind to and regulate purinergic receptors present on the surface of every cell in the body. ${ }^{92)}$ ATP has been found to be a co-neurotransmitter at every type of synaptic junction studied to date. ${ }^{93)}$ Excess extracellular ATP (eATP) is an activator of innate and adaptive immunity, ${ }^{94)}$ a danger signal and a damage-associated molecular pattern (DAMP) that is chemotactic for neutrophils. ${ }^{95)}$ It is also a potent regulator of microglial activation, death, and survival. ${ }^{96)}$

\section{Clinical implication}

Naviaux et al. $^{92)}$ used the maternal immune activation mouse model of gestational poly (IC) exposure and treatment with the non-selective purinergic antagonist suramin to test the role of purinergic signaling in $\mathrm{C} 57 \mathrm{BL} / 6 \mathrm{~J}$ mice. They found that antipurinergic therapy corrected 16 multisystem abnormalities that defined the ASD-like phenotype in this model. These included correction of the core social deficits and sensorimotor coordination abnormalities, prevention of cerebellar Purkinje cell loss, correction of the ultrastructural synaptic dysmorphology, and correction of the hypothermia, metabolic, mitochondrial, P2Y2 and P2X7 purinergic receptor expression, in addition to ERK1/2 and CAMKII signal transduction abnormalities. However, suramin as a treatment for prostate cancer causes numerous reversible complications such as severe urticarial reaction, adrenal damage, and impaired renal function. Neurotoxicity has been the most significant complication. ${ }^{97)}$

\section{Rapamycin}

\section{Mechanism}

Rapamycin is an immunosuppressant originally identified as an antifungal agent in isolates from Streptomyces hygroscopicus. ${ }^{98)}$ Rapamycin strongly binds to the FK506- binding protein (FKBP), and the complex sub- sequently binds and inhibits mTOR, a serine/threonine kinase implicated in transcription, cytoskeleton dynamics, ubiquitin-dependent protein degradation, autophagy, and membrane trafficking. ${ }^{99)}$ In the nervous system, mTOR regulates axon guidance, dendrite arborization, synaptogenesis, and synaptic plasticity. ${ }^{100)}$ Importantly, rapamycin treatment alleviates several pathogenic traits observed in in vivo and in vitro models of Alzheimer's disease, Parkinson's disease, and polyglutamine diseases. ${ }^{101)}$

\section{Clinical implication}

Tuberous sclerosis complex (TSC) is a genetic disorder with high rates of comorbid ASD that result from mutations of either TSC1 or TSC2. ${ }^{102)}$

Ehninger et al. ${ }^{103)}$ reported that a brief treatment with the mTOR inhibitor, rapamycin, in $T s c 2^{+/-}$adult mice rescues not only the synaptic plasticity, but also the behavioral deficits in the animal model of tuberous sclerosis. The social dysfunction and behavioral inflexibility of purkinje cell-specific $T s c 1$ mutant mice were also improved by rapamycin. ${ }^{104)}$

\section{Phosphatase and tensin homolog deleted on chromosome 10}

\section{Mechanism}

Phosphatase and tensin homolog deletion on chromosome 10 (PTEN) plays a pivotal role in controlling intracellular signaling for cell survival and proliferation by inhibiting the PI3K/Akt pathway. PTEN dysfunction is associated with several neoplastic diseases. ${ }^{105)}$ Unlike several cellular proteins which are activated by phosphorylation, PTEN is inactivated upon phosphorylation by specific kinases that phosphorylate serine and threonine residues in its $\mathrm{C}$-terminal region. Therefore, development of therapeutic agents that specifically target kinases and kinase-domain-containing proteins affecting PTEN would lead to the treatment of PTEN-related diseases.

Three genetic mutations in the PTEN gene (H93R in exon 4 and D252G and F241S in exon 7) have been identified which play a role in macrocephaly/autism syndrome. ${ }^{106)}$ Targeted inactivation of PTEN in the differentiated neurons of the cerebral cortex in mice resulted in increased response to sensory stimuli with neuronal hypertrophy, including hypertrophic and ectopic dendrites and axon tracts with increased synapses. This suggests that defects in PTEN cause macrocephaly and autistic syndrome in mice. ${ }^{107)}$ 


\section{Clinical implication}

Novel drug candidates to modulate PTEN are currently used for cancer treatment such as primary intraocular lymphoma, breast cancer, lung cancer, prostate cancer, T-cell Leukemia, B-non-Hodgkin's lymphoma and metastatic colorectal cancer. ${ }^{105)}$ In addition, 2-dimethyl-amino4,5,6,7-tetrabromo- $1 H$-benzimidazole (DMAT, CK2 inhibitor) and CT99021 regulate leptin and are used for diabetes and obesity treatment. ${ }^{108)}$ PTEN is known to have an important role in cardiovascular diseases, Alzheimer's disease, ASD and Parkinson's disease. ${ }^{105)}$ Napoli et al. ${ }^{109)}$ suggest a pathogenic mechanism of the PTEN-p53 axis in mice with aberrant social behavior. However, there is no evidence for treating psychiatric diseases including ASD with PTEN modulators and, therefore, further study is needed.

\section{CONCLUSION}

Pharmacotherapy in patients with ASD is focused on immediate problems in everyday life such as, anxiety, seizures, hyperactivity, aggressive behavior, self-harm and stereotypy. ASD, however, is a chronic and lifelong condition beginning in early childhood. Etiological pharmacotherapy, in addition to conservative treatment, is necessary. In the current article, we introduced pharmacological treatments based on currently ongoing ASD etiological pathogenic studies.

Although some medications based on neurotransmitter hypothesis such as cholinergic and glutamatergic reveals as effective drug and some of the treatments stands out mostly as an adjuvant therapy, some have no relation whatsoever regarding effects and pathogenesis. Research on the gene and synapse level medication was also introduced.

\section{Acknowledgments}

This work was supported by a grant of the Korean Health Technology R\&D Project, Ministry of Health and Welfare, Republic of Korea (No. A120029).

\section{REFERENCES}

1. Volkmar FR, Lord C, Bailey A, Schultz RT, Klin A. Autism and pervasive developmental disorders. J Child Psychol Psychiatry 2004;45:135-170.

2. Leyfer OT, Folstein SE, Bacalman S, Davis NO, Dinh E, Morgan J, et al. Comorbid psychiatric disorders in children with autism: interview development and rates of disorders. J Autism Dev Disord 2006;36:849-861.

3. Baio J. Prevalence of autism spectrum disorders--Autism and Developmental Disabilities Monitoring Network, 14 sites, United States, 2008. MMWR Surveill Summ 2012;61: 1-19.

4. American Psychiatric Association. Diagnostic and statistical manual of mental disorders: DSM-5. Washington, DC:American Psychiatric Association;2013.

5. Zuddas A. Autism assessment tools in the transition from DSM-IV to DSM-5. Eur Child Adolesc Psychiatry 2013;22: 325-327.

6. Celik G, Tahiroglu AY, Firat S, Avci A. Aripiprazole Improved Obsessive Compulsive Symptoms in Asperger's Disorder. Clin Psychopharmacol Neurosci 2011;9:134136.

7. Currenti SA. Understanding and determining the etiology of autism. Cell Mol Neurobiol 2010;30:161-171.

8. Giacobini E. Cholinergic foundations of Alzheimer's disease therapy. J Physiol Paris 1998;92:283-287.

9. Karvat G, Kimchi T. Acetylcholine elevation relieves cognitive rigidity and social deficiency in a mouse model of autism. Neuropsychopharmacology 2014;39:831-840.

10. Ghaleiha A, Ghyasvand M, Mohammadi MR, Farokhnia $\mathrm{M}$, Yadegari N, Tabrizi M, et al. Galantamine efficacy and tolerability as an augmentative therapy in autistic children: A randomized, double-blind, placebo-controlled trial. $J$ Psychopharmacol 2013. [Epub ahead of print]

11. Niederhofer H. Treating autism pharmacologically: also tacrine might improve symptomatology in some cases. $J$ Child Neurol 2007;22:1054.

12. Chez MG, Aimonovitch M, Buchanan T, Mrazek S, Tremb RJ. Treating autistic spectrum disorders in children: utility of the cholinesterase inhibitor rivastigmine tartrate. $J$ Child Neurol 2004;19:165-169.

13. Hertzman M. Galantamine in the treatment of adult autism: a report of three clinical cases. Int J Psychiatry Med 2003;33:395-398.

14. Nicolson R, Craven-Thuss B, Smith J. A prospective, open-label trial of galantamine in autistic disorder. J Child Adolesc Psychopharmacol 2006;16:621-629.

15. Niederhofer H, Staffen W, Mair A. Galantamine may be effective in treating autistic disorder. BMJ 2002;325:1422.

16. Hardan AY, Handen BL. A retrospective open trial of adjunctive donepezil in children and adolescents with autistic disorder. J Child Adolesc Psychopharmacol 2002;12: 237-241.

17. Chez MG, Buchanan TM, Becker M, Kessler J, Aimonovitch MC, Mrazek SR. Donepezil hydrochloride: a double-blind study in autistic children. J Pediatr Neurol 2003;1:83-88.

18. Handen BL, Johnson CR, McAuliffe-Bellin S, Murray PJ, Hardan AY. Safety and efficacy of donepezil in children and adolescents with autism: neuropsychological measures. J Child Adolesc Psychopharmacol 2011;21:43-50.

19. Carlson GC. Glutamate receptor dysfunction and drug targets across models of autism spectrum disorders. Pharmacol Biochem Behav 2012;100:850-854.

20. Sheldon AL, Robinson MB. The role of glutamate transporters in neurodegenerative diseases and potential opportunities for intervention. Neurochem Int 2007;51:333-355.

21. Fatemi SH, Halt AR, Stary JM, Kanodia R, Schulz SC, Realmuto GR. Glutamic acid decarboxylase 65 and $67 \mathrm{kDa}$ proteins are reduced in autistic parietal and cerebellar cortices. Biol Psychiatry 2002;52:805-810.

22. Yip J, Soghomonian JJ, Blatt GJ. Decreased GAD67 mRNA levels in cerebellar Purkinje cells in autism: pathophysiological implications. Acta Neuropathol 2007;113: 
559-568.

23. Brune CW, Kim SJ, Hanna GL, Courchesne E, Lord C, Leventhal BL, et al. Family-Based Association Testing of OCD-associated SNPS of SLC1A1 in an autism sample. Autism Res 2008;1:108-113.

24. Brown MS, Singel D, Hepburn S, Rojas DC. Increased glutamate concentration in the auditory cortex of persons with autism and first-degree relatives: a (1)H-MRS study. Autism Res 2013;6:1-10.

25. Ortinski PI, Dong J, Mungenast A, Yue C, Takano H, Watson DJ, et al. Selective induction of astrocytic gliosis generates deficits in neuronal inhibition. Nat Neurosci 2010;13:584-591.

26. Kim KC, Lee DK, Go HS, Kim P, Choi CS, Kim JW, et al. Pax6-dependent cortical glutamatergic neuronal differentiation regulates autism-like behavior in prenatally valproic Acid-exposed rat offspring. Mol Neurobiol 2014;49: 512-528.

27. Chez MG, Burton Q, Dowling T, Chang M, Khanna P, Kramer C. Memantine as adjunctive therapy in children diagnosed with autistic spectrum disorders: an observation of initial clinical response and maintenance tolerability. $J$ Child Neurol 2007;22:574-579.

28. Erickson CA, Posey DJ, Stigler KA, Mullett J, Katschke $\mathrm{AR}, \mathrm{McDougle}$ CJ. A retrospective study of memantine in children and adolescents with pervasive developmental disorders. Psychopharmacology (Berl) 2007;191:141-147.

29. Niederhofer H. Glutamate antagonists seem to be slightly effective in psychopharmacologic treatment of autism. $J$ Clin Psychopharmacol 2007;27:317-318.

30. Owley T, Salt J, Guter S, Grieve A, Walton L, Ayuyao $\mathrm{N}$, et al. A prospective, open-label trial of memantine in the treatment of cognitive, behavioral, and memory dysfunction in pervasive developmental disorders. J Child Adolesc Psychopharmacol 2006;16:517-524.

31. Ghaleiha A, Asadabadi M, Mohammadi MR, Shahei M, Tabrizi M, Hajiaghaee R, et al. Memantine as adjunctive treatment to risperidone in children with autistic disorder: a randomized, double-blind, placebo-controlled trial. Int $J$ Neuropsychopharmacol 2013;16:783-789.

32. Berry-Kravis E, Hessl D, Coffey S, Hervey C, Schneider $\mathrm{A}$, Yuhas J, et al. A pilot open label, single dose trial of fenobam in adults with fragile X syndrome. J Med Genet 2009;46:266-271.

33. Jacquemont S, Curie A, des Portes V, Torrioli MG, BerryKravis E, Hagerman RJ, et al. Epigenetic modification of the FMR1 gene in fragile $X$ syndrome is associated with differential response to the mGluR5 antagonist AFQ056. Sci Transl Med 2011;3:64ra1.

34. Berry-Kravis EM, Hessl D, Rathmell B, Zarevics P, Cherubini M, Walton-Bowen K, et al. Effects of STX209 (arbaclofen) on neurobehavioral function in children and adults with fragile $X$ syndrome: a randomized, controlled, phase 2 trial. Sci Transl Med 2012;4:152ra127.

35. Erickson CA, Veenstra-Vanderweele JM, Melmed RD, McCracken JT, Ginsberg LD, Sikich L, et al. STX209 (Arbaclofen) for Autism Spectrum Disorders: An 8-Week Open-Label Study. J Autism Dev Disord 2014;44:958-964.

36. Watanabe Y, Tsumura H, Sasaki H. Effect of continuous intravenous infusion of secretin preparation (secrepan) in patients with hemorrhage from chronic peptic ulcer and acute gastric mucosal lesion $(A G M L)$. Gastroenterol Jpn 1991;26 Suppl 3:86-89.

37. Charlton CG, Miller RL, Crawley JN, Handelmann GE, O'Donohue TL. Secretin modulation of behavioral and physiological functions in the rat. Peptides 1983;4:739742.

38. Fremeau RT Jr, Jensen RT, Charlton CG, Miller RL, O'Donohue TL, Moody TW. Secretin: specific binding to rat brain membranes. J Neurosci 1983;3:1620-1625.

39. Horvath K, Stefanatos G, Sokolski KN, Wachtel R, Nabors L, Tildon JT. Improved social and language skills after secretin administration in patients with autistic spectrum disorders. J Assoc Acad Minor Phys 1998;9:9-15.

40. Toda Y, Mori K, Hashimoto T, Miyazaki M, Nozaki S, Watanabe Y, et al. Administration of secretin for autism alters dopamine metabolism in the central nervous system. Brain Dev 2006;28:99-103.

41. Williams K, Wray JA, Wheeler DM. Intravenous secretin for autism spectrum disorders (ASD). Cochrane Database Syst Rev 2012;4:CD003495.

42. Lobmaier PP, Kunøe N, Gossop M, Waal H. Naltrexone depot formulations for opioid and alcohol dependence: a systematic review. CNS Neurosci Ther 2011;17:629-636.

43. Chamberlain RS, Herman BH. A novel biochemical model linking dysfunctions in brain melatonin, proopiomelanocortin peptides, and serotonin in autism. Biol Psychiatry 1990; 28:773-793.

44. Symons FJ, Thompson A, Rodriguez MC. Self-injurious behavior and the efficacy of naltrexone treatment: a quantitative synthesis. Ment Retard Dev Disabil Res Rev 2004; 10:193-200.

45. Campbell M, Anderson LT, Small AM, Adams P, Gonzalez NM, Ernst M. Naltrexone in autistic children: behavioral symptoms and attentional learning. $J$ Am Acad Child Adolesc Psychiatry 1993;32:1283-1291.

46. Stein DJ, van Honk J, Ipser J, Solms M, Panksepp J. Opioids: from physical pain to the pain of social isolation. CNS Spectr 2007;12:669-670, 672-674.

47. Cook MN. Dulcan's Textbook of Child and Adolescent Psychiatry. AM J Psychiatry 2012;169:541-542.

48. Bakermans-Kranenburg MJ, van Ijzendoorn MH. A sociability gene? Meta-analysis of oxytocin receptor genotype effects in humans. Psychiatr Genet 2014;24:45-51.

49. Landgraf R, Neumann ID. Vasopressin and oxytocin release within the brain: a dynamic concept of multiple and variable modes of neuropeptide communication. Front Neuroendocrinol 2004;25:150-176.

50. Inoue $T$, Kimura $T$, Azuma $C$, Inazawa $J$, Takemura $M$, Kikuchi T, et al. Structural organization of the human oxytocin receptor gene. J Biol Chem 1994;269:3245132456.

51. Gimpl G, Fahrenholz F. The oxytocin receptor system: structure, function, and regulation. Physiol Rev 2001;81: 629-683.

52. Wermter AK, Kamp-Becker I, Hesse P, Schulte-Körne G, Strauch $\mathrm{K}$, Remschmidt H. Evidence for the involvement of genetic variation in the oxytocin receptor gene (OXTR) in the etiology of autistic disorders on high-functioning level. Am J Med Genet B Neuropsychiatr Genet 2010; 153B:629-639.

53. Campbell DB, Datta D, Jones ST, Batey Lee E, Sutcliffe JS, Hammock EA, et al. Association of oxytocin receptor (OXTR) gene variants with multiple phenotype domains of autism spectrum disorder. J Neurodev Disord 2011;3:101112.

54. Hollander E, Bartz J, Chaplin W, Phillips A, Sumner J, Soorya L, et al. Oxytocin increases retention of social cognition in autism. Biol Psychiatry 2007;61:498-503.

55. Guastella AJ, Einfeld SL, Gray KM, Rinehart NJ, Tonge 
$\mathrm{BJ}$, Lambert $\mathrm{TJ}$, et al. Intranasal oxytocin improves emotion recognition for youth with autism spectrum disorders. Biol Psychiatry 2010;67:692-694.

56. Andari E, Duhamel JR, Zalla T, Herbrecht E, Leboyer M, Sirigu A. Promoting social behavior with oxytocin in high-functioning autism spectrum disorders. Proc Natl Acad Sci U S A 2010;107:4389-4394.

57. Kosaka H, Munesue T, Ishitobi M, Asano M, Omori M, Sato $\mathrm{M}$, et al. Long-term oxytocin administration improves social behaviors in a girl with autistic disorder. BMC Psychiatry 2012;12:110.

58. Leckman JF. Variations in maternal behavior--oxytocin and reward pathways--peripheral measures matter?! Neuropsychopharmacology 2011;36:2587-2588.

59. Churchland PS, Winkielman P. Modulating social behavior with oxytocin: how does it work? What does it mean? Horm Behav 2012;61:392-399.

60. Guastella AJ, Hickie IB, McGuinness MM, Otis M, Woods EA, Disinger HM, et al. Recommendations for the standardisation of oxytocin nasal administration and guidelines for its reporting in human research. Psychoneuroendocrinology 2013;38:612-625.

61. Levy SE, Hyman SL. Complementary and alternative medicine treatments for children with autism spectrum disorders. Child Adolesc Psychiatr Clin N Am 2008;17: 803-820.

62. Davis MP, Darden PM. Use of complementary and alternative medicine by children in the United States. Arch Pediatr Adolesc Med 2003;157:393-396.

63. Kim P, Park JH, Kwon KJ, Kim KC, Kim HJ, Lee JM, et al. Effects of Korean red ginseng extracts on neural tube defects and impairment of social interaction induced by prenatal exposure to valproic acid. Food Chem Toxicol 2013;51:288-296.

64. Soden SE, Lowry JA, Garrison CB, Wasserman GS. 24-hour provoked urine excretion test for heavy metals in children with autism and typically developing controls, a pilot study. Clin Toxicol (Phila) 2007;45:476-481.

65. Barbaresi WJ, Colligan RC, Weaver AL, Katusic SK. The incidence of clinically diagnosed versus research-identified autism in Olmsted County, Minnesota, 1976-1997: results from a retrospective, population-based study. J Autism Dev Disord 2009;39:464-470.

66. Desoto MC, Hitlan RT. Sorting out the spinning of autism: heavy metals and the question of incidence. Acta Neurobiol Exp (Wars) 2010;70:165-176.

67. Blaurock-Busch E, Amin OR, Dessoki HH, Rabah T. Toxic metals and essential elements in hair and severity of symptoms among children with autism. Maedica (Buchar) 2012;7:38-48

68. Tamm C, Duckworth J, Hermanson O, Ceccatelli S. High susceptibility of neural stem cells to methylmercury toxicity: effects on cell survival and neuronal differentiation. J Neurochem 2006;97:69-78.

69. Bellinger DC. Very low lead exposures and children's neurodevelopment. Curr Opin Pediatr 2008;20:172-177.

70. Lim MH, Kwon HJ. Environmental Factors in Autism and Autistic Spectrum Disorder. J Korean Acad Child Adolesc Psychiatry 2011;22:3-9.

71. Lee BK, Ahn KD, Lee SS, Lee GS, Kim YB, Schwartz BS. A comparison of different lead biomarkers in their associations with lead-related symptoms. Int Arch Occup Environ Health 2000;73:298-304.

72. Dietrich KN, Ware JH, Salganik M, Radcliffe J, Rogan WJ, Rhoads GG, et al; Treatment of Lead-Exposed
Children Clinical Trial Group. Effect of chelation therapy on the neuropsychological and behavioral development of lead- exposed children after school entry. Pediatrics 2004; 114:19-26.

73. Nataf R, Skorupka C, Amet L, Lam A, Springbett A, Lathe R. Porphyrinuria in childhood autistic disorder: implications for environmental toxicity. Toxicol Appl Pharmacol 2006;214:99-108.

74. Adams JB, Audhya T, McDonough-Means S, Rubin RA, Quig D, Geis E, et al. Effect of a vitamin/mineral supplement on children and adults with autism. BMC Pediatr 2011;11:111.

75. Krajcovicova-Kudlackova M, Valachovicova M, Mislanova C, Hudecova Z, Sustrova M, Ostatnikova D. Plasma concentrations of selected antioxidants in autistic children and adolescents. Bratisl Lek Listy 2009;110:247-250.

76. McGrath J, Feron F, Eyles D, Mackay-Sim A. Vitamin D: the neglected neurosteroid? Trends Neurosci 2001;24:570572.

77. Cannell JJ. Autism and vitamin D. Med Hypotheses 2008; 70:750-759.

78. Cui X, McGrath JJ, Burne TH, Mackay-Sim A, Eyles DW. Maternal vitamin $D$ depletion alters neurogenesis in the developing rat brain. Int J Dev Neurosci 2007;25:227-232.

79. Hayashi E. Seasonal changes in sleep and behavioral problems in a pubescent case with autism. Psychiatry Clin Neurosci 2001;55:223-224.

80. Cannell JJ. Autism, will vitamin D treat core symptoms? Med Hypotheses 2013;81:195-198.

81. Golnik AE, Ireland M. Complementary alternative medicine for children with autism: a physician survey. J Autism Dev Disord 2009;39:996-1005.

82. Yehuda S, Rabinovitz S, Mostofsky DI. Mediation of cognitive function by high fat diet following stress and inflammation. Nutr Neurosci 2005;8:309-315.

83. James S, Montgomery P, Williams K. Omega-3 fatty acids supplementation for autism spectrum disorders (ASD). Cochrane Database Syst Rev 2011;(11):CD007992.

84. Richardson AJ, Ross MA. Fatty acid metabolism in neurodevelopmental disorder: a new perspective on associations between attention-deficit/hyperactivity disorder, dyslexia, dyspraxia and the autistic spectrum. Prostaglandins Leukot Essent Fatty Acids 2000;63:1-9.

85. Williams K, Marraffa C. No evidence yet to support omega-3 fatty acids as a treatment for autism. J Paediatr Child Health 2012;48:534-536.

86. Berk M, Malhi GS, Gray LJ, Dean OM. The promise of $N$-acetylcysteine in neuropsychiatry. Trends Pharmacol Sci 2013;34:167-177.

87. Arakawa M, Ito Y. N-acetylcysteine and neurodegenerative diseases: basic and clinical pharmacology. Cerebellum 2007;6:308-314.

88. Kau KS, Madayag A, Mantsch JR, Grier MD, Abdulhameed O, Baker DA. Blunted cystine-glutamate antiporter function in the nucleus accumbens promotes cocaineinduced drug seeking. Neuroscience 2008;155:530-537.

89. Lushchak VI. Glutathione homeostasis and functions: potential targets for medical interventions. J Amino Acids 2012;2012:736837.

90. Villagonzalo KA, Dodd S, Dean O, Gray K, Tonge B, Berk M. Oxidative pathways as a drug target for the treatment of autism. Expert Opin Ther Targets 2010;14: 1301-1310.

91. Hardan AY, Fung LK, Libove RA, Obukhanych TV, Nair $\mathrm{S}$, Herzenberg LA, et al. A randomized controlled pilot 
trial of oral $N$-acetylcysteine in children with autism. Biol Psychiatry 2012;71:956-961.

92. Naviaux RK, Zolkipli Z, Wang L, Nakayama T, Naviaux $\mathrm{JC}$, Le TP, et al. Antipurinergic therapy corrects the autism-like features in the poly(IC) mouse model. PLoS One 2013;8:e57380.

93. Abbracchio MP, Burnstock G, Verkhratsky A, Zimmermann $\mathrm{H}$. Purinergic signalling in the nervous system: an overview. Trends Neurosci 2009;32:19-29.

94. Junger WG. Immune cell regulation by autocrine purinergic signalling. Nat Rev Immunol 2011;11:201-212.

95. Zhang Q, Raoof M, Chen Y, Sumi Y, Sursal T, Junger W, et al. Circulating mitochondrial DAMPs cause inflammatory responses to injury. Nature 2010;464:104-107.

96. Harada K, Hide I, Seki T, Tanaka S, Nakata Y, Sakai N. Extracellular ATP differentially modulates Toll-like receptor 4-mediated cell survival and death of microglia. J Neurochem 2011;116:1138-1147.

97. Kaur M, Reed E, Sartor O, Dahut W, Figg WD. Suramin's development: what did we learn? Invest New Drugs 2002; 20:209-219.

98. Singh K, Sun S, Vézina C. Rapamycin (AY-22,989), a new antifungal antibiotic. IV. Mechanism of action. J Antibiot (Tokyo) 1979;32:630-645.

99. Dennis PB, Fumagalli S, Thomas G. Target of rapamycin (TOR): balancing the opposing forces of protein synthesis and degradation. Curr Opin Genet Dev 1999;9:49-54.

100. Troca-Marín JA, Alves-Sampaio A, Montesinos ML. An increase in basal BDNF provokes hyperactivation of the Akt-mammalian target of rapamycin pathway and deregulation of local dendritic translation in a mouse model of Down's syndrome. J Neurosci 2011;31:94459455.
101. Won H, Mah W, Kim E. Autism spectrum disorder causes, mechanisms, and treatments: focus on neuronal synapses. Front Mol Neurosci 2013;6:19.

102. Jeste SS, Sahin M, Bolton P, Ploubidis GB, Humphrey A. Characterization of autism in young children with tuberous sclerosis complex. J Child Neurol 2008;23:520-525.

103. Ehninger D, Han S, Shilyansky C, Zhou Y, Li W, Kwiatkowski DJ, et al. Reversal of learning deficits in a Tsc2+/- mouse model of tuberous sclerosis. Nat Med 2008; 14:843-848.

104. Tsai PT, Hull C, Chu Y, Greene-Colozzi E, Sadowski AR, Leech JM, et al. Autistic-like behaviour and cerebellar dysfunction in Purkinje cell Tsc1 mutant mice. Nature 2012;488:647-651.

105. Boosani CS, Agrawal DK. PTEN modulators: a patent review. Expert Opin Ther Pat 2013;23:569-580.

106. Butler MG, Dasouki MJ, Zhou XP, Talebizadeh Z, Brown $\mathrm{M}$, Takahashi TN, et al. Subset of individuals with autism spectrum disorders and extreme macrocephaly associated with germline PTEN tumour suppressor gene mutations. $J$ Med Genet 2005;42:318-321.

107. Kwon CH, Luikart BW, Powell CM, Zhou J, Matheny SA, Zhang $\mathrm{W}$, et al. Pten regulates neuronal arborization and social interaction in mice. Neuron 2006;50:377-388.

108. Ning K, Miller LC, Laidlaw HA, Watterson KR, Gallagher $\mathrm{J}$, Sutherland $\mathrm{C}$, et al. Leptin-dependent phosphorylation of PTEN mediates actin restructuring and activation of ATPsensitive $K^{+}$channels. J Biol Chem 2009;284:9331-9340.

109. Napoli E, Ross-Inta C, Wong S, Hung C, Fujisawa Y, Sakaguchi D, et al. Mitochondrial dysfunction in Pten haplo-insufficient mice with social deficits and repetitive behavior: interplay between Pten and p53. PLoS One 2012;7:e42504. 